\title{
Probing the Surveillant Assemblage: on the dialectics of surveillance practices as processes of social control.*
}

\author{
Sean P. Hier ${ }^{1}$
}

\begin{abstract}
Recent dialogue on the contemporary nature of information and data gathering techniques has incorporated the notion of assemblages to denote an increasing convergence of once discrete systems of surveillance. The rhizomatic expansion of late modern 'surveillant assemblages' is purported not only to enable important transformations in the p urpose and intention of surveillance practices, but to facilitate a partial democratization of surveillance hierarchies. Seeking to account for the forces and desires which give rise to, and sustain, surveillant assemblages, this paper explicates the workings of a dialectic embedded in many surveillance practices to reveal a polarization effect involving the simultaneous leveling and solidification of hierarchies. Empirical data from the intensification of welfare monitoring are presented to illustrate the dialectics of surveillance practices as processes of social control.
\end{abstract}

\section{Problematics}

In the early pages of her essay When Old Technologies Were New, Carolyn Marvin (1988) argues that the history of electronic media reveals less about the evolution of technical efficiencies in communication than a series of arenas for negotiating issues crucial to the conduct of social life. Among those issues, who is 'inside' and who is 'outside', who may speak and who may not and who possesses authority to be believed. Here, she maintains, the focus of communication is shifted from 'the instrument' to 'the drama' in which diverse social groups perpetually negotiate power, authority, representation and knowledge with whatever resources they lave at their disposal. It follows that, although the development of advanced forms of electronic media may serve to alter the perceived effectiveness of one group's surveillance over others, the enduring drama of human agents and technological innovations has more to do with the social conflicts and

* I am grateful for the reflection on an early draft offered by David Lyon and Candace Kemp, and for the useful comments forwarded by the anonymous reviewers. I would also like to acknowledge the financial support provided through a post-doctoral fellowship on the surveillance project at Queen's University, Canada. ${ }^{1}$ Department of Sociology, University of Victoria, Victoria British Columbia Canada V8W 3P5, mailto:hiers@post.queensu.ca 
practices which serve to illuminate new communication devices than it does with the particular instrument of mediation, surveillance or social control.

In the last two decades, significant alterations in the echnological character of surveillance practices have transpired to the extent that researchers have started to rethink dominant theoretical and conceptual assumptions, particularly where the role of the state is concerned. Offering what has become a conceptual benchmark in the surveillance literature, Kevin Haggerty and Richard Ericson (2000) incorporate the notion of assemblages to denote the increasing convergence of once discrete systems of surveillance. They argue that the late modern period has ushered in the proliferation of information and data gathering techniques which operate to break the human body into a number of discrete signifying data flows. Reassembled as 'functional hybrids' whose unity is found solely in temporal moments of interdependence, resulting surveillance simulations bring together a seemingly limitless range of information to formulate categorical images or risk data profiles which render otherwise opaque flows of information comprehensible. Conceptualizing the surveillant assemblage as a sequence of processes which approach the human body as a cyborg/flesh amalgamation which is secondarily directed back towards embodied individuals for a plethora of reasons, not only do they deduce that there has transpired important changes in the form and intention of surveillance, but this line of reasoning is extended to affirm that a partial democratization of surveillance hierarchies has ensued.

Whilst it can be conceded that the manifest character of surveillance has been significantly enhanced through technological and communicative innovation, enabling certain transformations in the purposes of surveillance, this paper probes certain key assumptions of the emergent 'surveillant assemblage'. It is argued that the assemblage model places an exaggerated degree of importance, however implicitly, on the social and cultural effects of the technological capabilities of contemporary surveillance practices which serves to obscure rather than clarify the enduring drama of human agents and surveillance technologies. The problem derives from the fact that the fundamental object of contestation, or the primary point of conceptual departure, is the supposition that the impetus to surveillance comes ostensibly from above (variations on which take the form of the panoptic power of the state), so when surveillance technologies began to facilitate the monitoring of a wider population base this has been interpreted as a shift in the cultural character of surveillance (op. cit:610) with its concomitant leveling of hierarchies. In an effort to account for the more fundamental forces and desires which give rise to, and sustain, surveillant assemblages, the functioning of a dialectic embedded in many surveillance practices is revealed in the present analysis to contribute to a polarization effect involving the simultaneous leveling and solidification of hierarchies. The impetus, however, is not located in powerful social actors or elite bodies. Rather, it is purported that considerable foundational support derives from popular social grievances, various antagonisms directed at a variety of socially constituted risk groups from below, which come to secondarily culminate in the intensification of top-down regimes of surveillance.

The discussion is presented over three sections. The first section offers an overview of the central tenets of the surveillant assemblage as it is conceptualized by Haggerty and Ericson. Of particular 
concern is their implicit yet evident insinuation that the technological composition of contemporary information and data gathering techniques has been the primary factor contributing to a partial democratization of surveillance hierarchies. This is followed in the second section by a critical assessment of the surveillant assemblage. Drawing from Thomas Mathiesen's conceptualization of the viewer society which explicates the dialectical interaction of panoptical (top down) and synoptical (bottom up) processes transmitted largely through the media of mass communications, it is demonstrated how a complete understanding of contemporary surveillance systems must take seriously the social and cultural forces which give rise to, and sustain, assemblages. The third section offers empirical data from aggressive changes to the monitoring of poor single mothers who rely on social assistance in the Canadian province of Ontario to demonstrate how the formation of surveillant assemblages often augment already existing social disadvantages as much as they contribute to their eradication, but that they are not necessarily top down hierarchical processes in the first instance, although they often assume such a form in the last instance.

\section{The Surveillant Assemblage}

The contemporary literature concerned with surveillance has demonstrated a tendency to gravitate towards the metaphoric imagery expatiated in George Orwell's prescient vision of Oceania and, more commonly, Michel Foucault's abstraction of the panoptic. For Orwell, the future promised state totalitarianism, exemplified by the 'telescreen', the 'thought police' and categorically selective social monitoring practices. So went the argument, the constant visibility of Big Brother served as a mechanism of repression oriented towards inducing and maintaining compliance and social order. Foucault, by contrast, understood the visible manifestations of modern surveillance as having been increasingly rendered unnecessary through the normalizing gaze of the disciplines and the constitution of self-regulating subjects. Well beyond a mechanism of repression, panoptic observation involved a productive reflection on the self to the extent that the dispersion of truth claims across a range of social institutions served to generate disciplinary practices and the exercise of power over oneself.

In Haggerty and Ericson's assessment (2000), what emerges as problematic through this protracted reliance on Foucault and, less commonly, Orwell is that such accounts fail to embrace seriously contemporary developments in surveillance techniques. Among other things, they contend that contemporary surveillance practices stretch far beyond the state, their technological capabilities problematize a reliance on 18th and 19th century total institutions and, far from the negative connotations that tend to be attached to surveillance, many surveillance practices today are not only supported but encouraged by those who serve as the primary targets of data gathering systems. What this intimates for Haggerty and Ericson is that, rather than recasting Orwellian or Foucauldian imagery to fit the technological particularities of contemporary surveillance (i.e. electronic panopticon, super panopticon), it is more beneficent to chart alternative theoretical and conceptual terrain. 
In doing so, they invoke Delueze and Guattari's concept of assemblages to denote the increasing convergence of once discrete information and data gathering systems. Pronouncing surveillance as one of the main institutional components of late modernity, the 'surveillant assemblage' is put forth to distance their conceptual endeavor from the episteme of discretely structured objects of stability and constancy. Incorporated to explicate the functional multiplicity of a heterogeneity of objects whose unity is located in moments of interdependence, the notion of the assemblage is adopted to capture the configurational character of the present- in the words of Deleuze and Guattari (1987: 406), 'veritable inventions'.

For Haggerty and Ericson, what is notable about the emergent surveillant assemblage is that, driven by desires to bring component parts together into functional systems - variations on which take the form of control, governance, security and profit - an exponential increase in, and convergence of, surveillance technologies has ensued. They explain that surveillance capabilities are increasingly directed towards the human body as a distinctive composition of life forms and webs of information. These processes involve abstractions from, or data doubles on, organic hybrids, such that a protracted reliance develops on machines not only to register but record otherwise discrete observations. Maintaining that we are only beginning to appreciate how surveillance is driven by the desire to integrate component parts into wider systems, they insist that data simulations are not simply 'representational' by nature, but involve a more advanced form of pragmatics having to do with their instrumental efficacy in making discriminations among divergent populations.

What this indicates about contemporary systems of surveillance is that they do not approach the embodied individual for purposes of punishment or control. Instead, with the assistance of various information technologies the body is broken into a series of data flows, such that the introduction of 'breaks' or divisions into otherwise free-flowing phenomena contributes to the creation of physical and cognitive spaces that capture, striate and appropriate flows. In this sense, it is not the personal identity of the embodied individual but rather the actuarial or categorical profile of the collective which is of foremost concern to the surveillant assemblage. The temporal culmination of the striation or appropriation of flows, in turn, serves as a mechanism to make visible that which is opaque, to bring tangibility and coherence to informational stimuli which reside beyond the normal range of human perception. The surveillant assemblage, in other words, can be understood as a mechanism of 'visualization', giving rise to a cyborg flesh/technology amalgamation comprised of pure information which is only then redirected back towards the body for a multitude of reasons.

To complete their conceptualization, Haggerty and Ericson highlight the 'rhizomatic' character of the surveillant assemblage. Borrowing from Delueze and Guattari, they explain that rhizomes are plants which grow in surface extensions through interconnected roots oriented in a vertical fashion. That the rhizome grows across interconnected roots which throw up 'shoots' in different locations, fracture or discontinuity in the root structure is inconsequential for the overall growth potential of the infrastructure. The rhizome serves as a fitting metaphor to capture the essence of contemporary surveillance, they contend, for it is not that there exists a centralized structure (or arborescent 'trunk') which coordinates contemporary 'branches' of surveillance, but that 
surveillant technologies operate by variation and disjunction, intensification and horizontally fragmented expansion.

There is no doubt that developments in contemporary surveillance techniques have opened spaces not previously accessible (or not on such a wide scale) to divergent agencies and organizations. The problem which emerges, however, is that Haggerty and Ericson deduce from their conceptualization that the rhizomatic character of contemporary surveillance has worked to transform previously existing hierarchies of surveillance. In contrast to panoptical conceptions of surveillance, where the few are able to visualize the many, they maintain that the rhizomatic expansion of surveillance throughout all sectors of society '....cumulatively highlight a fractured rhizomatic criss-crossing of the gaze such that no major population groups stand irrefutably above or outside the surveillant assemblage' (op. cit.:618). They attribute this partial democratization of surveillance hierarchies to the fact that surveillance has become rhizomatic (op. cit.:617), recognizing that although surveillance monitoring remains differential in its various application(s), there has transpired a 'synoptic shift' of sorts, whereby bottom-up forms of observation are now at work (op. cit.:618) which parallel Foucault's conception of panopticism. The point they wish to make is that the 'creeping' character of surveillance infrastructures, made possible by advances in information and communication technologies across state and extra-state agencies, have enabled the many to scrutinize the few like never before, rendering a more extended range of the population susceptible to surveillance in its many forms.

\section{Probing the SurveillantAssemblage}

Whilst it can surely be conceded that advances in information and data gathering capabilities have facilitated the formation of new data gathering techniques through a rhizomatic expansion well beyond the state, it is crucial to remain cognizant of the fact that these new patterns or 'shoots' are neither random nor is their fundamental character unique to the present. They involve, in the words of David Lyon (2001), 'leaky containers', once discrete public and private sector informational infrastructures increasingly coming into contact. Although this characterizes an increasing pattern in surveillance, particularly where electronic or automated surveillance is concerned, it is important not to lose sight of the fact that these infrastructures remain connected to, or develop out of, 'early modern' systems of surveillance, underscored by the desire to coordinate and control populations, to make 'visible' that which evades immediate perception- the panoptic impulse. By arguing that there has transpired a 'late modern' rhizomatic expansion in the cultural constituent which is surveillance, Haggerty and Ericson place an exaggerated degree of importance on the social and cultural effects of the capabilities of contemporary surveillance technologies. For it is not that surveillance has become rhizomatic in that elusive temporality identified as the late modern period, but rather surveillance, as intimately tied to the expansion of information and communication technologies, and hence to the rise of modernity, has always been rhizomatic. Considering that the metaphor of the rhizome is used not only to capture the expansion and resilience of surveillant assemblages but to simultaneously signify its leveling effect on surveillance (and, by corollary, social) hierarchies, to achieve a more complete appreciation of the significance of manifesting 
surveillance technologies ('shoots') it is necessary to probe deeper into the divergent social and cultural forces and desires which give rise to, and are component parts of, surveillant assemblages.

One intriguing line of reasoning is found in Mathiesen's (1997) discussion of the 'viewer society', where he calls into question Foucault's (1977:216) invocation of Julius' proclamation that the problem of the modern age is '...[t]o procure for a small number, or even for a single individual, the instantaneous view of a great multitude'. For Mathiesen, what is missing- or more accurately, ignored - in Foucault's account of the panoptical-surveillance society is an incorporation of the role of the mass media. He explains that accompanying the shift observed by Foucault from the theatrical expression of the sovereign to the disciplinary-surveillance society has been the parallel rise of the modern mass media. What this implies for Mathiesen is that, whereas the few are vested with the ability to see the many under panoptical surveillance, the many have increasingly become accustom to seeing, and thereby contemplating, the actions of the few with the rise and expansion of mass mediated communication systems, particularly television.

Captured by the appellation of the synoptic, Mathiesen postulates that synopticism may be used to represent situations whereby large numbers of people are able to focus on something in common. Conceptualized as an opposing situation to panoptical supervision, he contends that synoptical observation represents a concurrent force which accelerated through the modern period in intimate interaction - even fusion - with the panoptic. For as Mathiesen outlines, it was at precisely the same time that Foucault identified the rise of the modern prison and panopticism that the media of mass communications in the form of the press emerged. Presupposed by important social conditions including the changing role of the citizen and the development of a sizable middle class, the mass distribution of the newspaper enabled those of similar social status to visualize on a much wider scale not only others with whom they presumably identified but the actions and intentions of those with whom they did not. The subsequent communicative expansion of other media - film, radio, television - significantly contributed to the advancement of this capability, but it was also facilitated by the distributive capacities of technological flows in the form of the train, steamship, telegraph and the harnessing of electricity. It is important to note, too, that developments in the expansion of mass communications were presupposed by a social structure which increasingly desired mobility, speed and information, facilitating the distanciation of time and space and the disembedding of social relations.

That synoptical processes developed in tandem with panoptical ones, from the Inquisition to the Internet, leads Mathiesen to the argument that the synoptic and the panoptic are mutually implicating processes which serve reciprocal functions. What is unique to the contemporary context, he adds, is that it is technologically feasible for panoptical and synoptical impulses to merge through the same technology. When abduction footage from video surveillance tapes showing two-year old James Bulger being escorted out of the Bootle Strand Shopping Centre near Liverpool were synoptically revealed to a worldwide audience in the early 1990s, for example, the panoptic impulse was strikingly apparent: more surveillance, tighter security. The video coverage neither served to deliver James Bulger from the wrath of his murderers any more than footage from a Solham recreational centre camera contributed to the deliverance of Holly 
Wells and Jessica Chapman. To paraphrase Colin Hay (1996), what the footage of James Bulger's abduction did do is explicate how the society of the spectacle reaps its revenge upon the society of surveillance: the private, depersonalizing CCTV coverage of the failed disciplinary routines of the mall became public spectacle, as footage showing James Bulger escorted from the centre was thrust into newspapers, magazines and television news broadcasts for the visual consumption, and condemnation, of an international audience.

Hence, in contrast to Foucault's understanding of the modern subject as the culmination of dispersed, non-visible panoptical processes oriented towards the transformation of the soul, Mathiesen finds it more feasible to explain these processes as fulfilled by the visibility of modern synopticon. Far from Foucault's panoptical gaze, where surveillance and punishment are removed from open view, the synoptic embraces the visual in the most emphatic manner because the synopticon is thoroughly visual and visualizing. Not only do synoptical processes enable the many to focus on something of common stock but Mathiesen argues that they constitute a more or less total pattern of visualization, intimately tied to the impulse to panoptic visualization. In recent memory, no event exemplifies the dialectical interaction of synoptical forces and panoptical desires more cogently than the mediation of the terrorist attacks on the World Trade Centre of 11 September 2001. Through sustained graphic visual representation of the collapsing Twin Towers, the fusion of the synoptic and the panoptic was revealed: repeated exposure to the fantastic spectacle served to invite a global audience to consume the hybrid image of fascination and repulsion whilst those same images served as, and remain, the central discursive resource oriented towards consolidating panoptical aspirations through the intensification of information gathering, data sharing and risk management techniques. In its many forms, surveillance stands as a cause as well as an effect of intensified practices of social monitoring and information gathering.

\section{Surveillance Practices as Processes of Social Control}

With an exaggerated degree of importance assigned to the social and cultural effects of the technological capabilities of contemporary surveillance practices, the surveillant assemblage rests on the assumption that the impetus to surveillance comes fundamentally from above, from elite, police or government. As surveillance technologies increasingly made possible the monitoring of a wider portion of the population, this has been interpreted as a shift in the cultural character of surveillance hierarchies. Yet, the fallout of an acceleration in the expansion of surveillance infrastructures has not been the tearing away of surveillance hierarchies sui generis, but rather a polarization of hierarchies has ensued in the form of a simultaneous leveling and solidification of already existing fractures.

One form in which the solidification of surveillance hierarchies assumes is a dynamic set of practices conceptualized in terms of social control processes. Admittedly, the epistemology of social control, which has enjoyed a long history in sociological writings, has tended to produce a kind of determinism implying that there exists an acting 'society', 'social structure' or remote governmental body that acts upon an otherwise homogenous population in a singular and uniform 
manner. It is for this reason that recent sociological discourse on social control has sought to understand the workings of governmental projects by drawing attention to the importance of the intersection of state practices with processes and techniques of self formation. Maintaining a conceptual emphasis on the role of human agency, as well as the configurational character of state policy, the popular dimensions that presuppose social control processes in their manifest form have been prioritized (cf. Hunt 1999; Hier 2003). What has hitherto been ignored is the role that surveillance practices in terms of the mutual conditioning of synoptical forces and panoptical desires have to play in the formation of processes of social control.

Perhaps no example demonstrates how the dialectical constitution of surveillance finds stability in social control processes better than contemporary approaches to single mothers and welfare. Welfare recipients have long been subjected to moralized regimes of surveillance. Little (1994, 1997), for instance, presents compelling analyses of the extent to which the actions and agency of single mothers collecting welfare in the Canadian province of Ontario have been surveilled by agents of the state as well as those acting in collusion with the state- neighbours, teachers, landlords and charity workers. Whilst these forms of morally regulating the activities of poor single mothers, relying to a large extent on 'informers' or 'rats', remain prominent, Gilliom $(1997,2001)$ has reported on how 'old forms' of morally regulating poor single mothers in Ohio have combined with the potentialities of 'CRIS-E', the Client Registration System- Enhanced.

A high-tech surveillance system capable of monitoring all 'legitimate' forms of welfare recipients' income for risks of infraction or abuse, CRIS-E brings together state-wide databases to manage and evaluate, surveil and administer welfare allowances. What is so alarming about the system is not the state's stronghold over poor single mothers, but the disciplinary effects of CRIS-E. As Gilliom relates through interview data, although single mothers accessing welfare fully realize that the state does not provide enough in allowances to meet basic necessities, many refrain from taking 'side jobs' for fear of termination from welfare or, equally as feared, the 'inspection'. What the latter involves is state agents interrogating recipients to ascertain their 'deservingness' or 'worthiness' under conditions of secrecy as to the purpose of the inspection. Indeed, Gilliom is correct to observe that it is hard to image a more compelling example of the politics of vision and how surveillance operates as a form of domination over the body, contributing to the exasperation rather than leveling of hierarchies of surveillance.

The implementation of CRIS-E draws attention to important 'panoptic' developments in the regulation of poor single mothers, but Gilliom's discussion fails to fully account for the synoptical desires motivating the development of such a system. Going some distance to accommodate for this shortcoming, Margaret Little (2001) has sought to understand the consequences of New Right politics on the surveillance of poor single mothers accessing welfare in Ontario since 1995. As she argues, by playing on myths surrounding single mothers who access government allowance as lazy criminals who present a significant risk to the welfare system, the state and ultimately the moral underpinnings of 'society', the government has been afforded popular legitimacy to significantly reduce allowances for poor single mothers whilst at the same time enhancing a variety of surveillance mechanisms which govern their lives. 
When the conservative government under the leadership of former Premier Mike Harris ascended to power in Ontario in 1995, it was on a New Right policy platform combining a neo-liberal emphasis on reducing the size and role of government with a neo-conservative focus oriented towards 'getting tough' with moral deviants. One of the central discursive objects of contention in the Harris Tories' campaign strategy was 'the welfare recipient'. Riding on a populist platform reflected in the nation's mainstream press, the conservative's agenda included a strong codified discourse focusing on welfare dependency, responsibilization and levels of benefits that 'we can't afford' (Knight 1998:109). At the start of their campaign, the conservatives were significantly behind the liberals in the polls, as the liberals enjoyed over 50\% support with the conservatives at $25 \%$. Voicing a consistent and clear commitment to cutting government spending, introducing mandatory workfare and cutting welfare costs, as well as taking a hard line with juvenile offenders and rescinding 'useless' employment equity/race relations policies, the conservative's media strategies memorably involved Mike Harris standing in front of a mock road sign reading 'Welfare, Ontario', to the point that by the fourth week of the campaign the liberal's lead was vanishing (ibid).

Particularly noteworthy about the conservative's election platform was not simply that they assigned a conflated sense of blame for high levels of government spending to moral deviants, welfare recipients and criminals, but an additional level of failure was attributed to the structure of government itself. This strategy effectively served to set up two discursive antagonisms: first it situated 'honest citizens' against those on the social and moral margins, individualizing blame and social responsibility; and second, it problematized the role of the state in social welfare, identifying responsible government as a problem in and of itself. As Mathiesen maintains, the visual domain of synopticon vis-à-vis the press represents a totalizing message system tailored to the 'requirements' of modernity, functioning to constrain popular consciousness in the interests of power and control. 'Inside synopticon', he laments, '....the material is purged of everything but the criminal - what was originally a small segment of a human being becomes the whole human being - whereupon the material is hurled back into the open society as stereotypes and panic-like, terrifying stories about individual cases' (op. cit:231). By articulating a generalized sense of crisis along the dual axes of the political and the transgressive, the Harris campaign served to tap into populist anxieties pertaining to middle-class discontentment with state spending, public safety and welfare abuse.

Understood in the context of the wider political landscape of the early 1990s, the conservatives' ascendancy to power was set against the backdrop of rising provincial debt, severe recession, growing unemployment and an NDP government perceived as a failure in the eyes of business and labour. Attributing responsibility to careless government spending, able-bodied workers who refuse to participate in the labour force and single mothers living in subsidized housing projects with male partners akin to brothels (cf. Little 1999), the Harris Tories managed to muster enough momentum to win $45 \%$ of the popular vote. Their first term in power brought a reduction in welfare benefits by nearly $22 \%$, the implementation of a 'workfare' programme and reduced allowances to those who seek retraining and educational advancement. But nothing was so devastating as the mechanisms of surveillance implemented under the Harris government's 
anti-fraud provisions.

Designed to 'stamp out fraud', several 'verification measures' were enacted which involved welfare workers demanding literally hundreds of pieces of information from poor single mothers (Little 2001). With a wider concern to rationalize the administration of welfare, old paper documents were increasingly transferred to computer files. Over the duration of these processes, it was discovered that several pieces of verifying documentation were missing from welfare recipients' files. Subsequently, everything from assets, documented employment histories and relationships with ex-spouses/lovers to the sale of personal belongings- some of which transpired over a decade prior to the request for documentation- were demanded. The stresses placed on women who were faced with fewer financial resources to track down such information (to offset childcare, travel fees and service charges), combined with barriers such as those faced by aboriginal women who were forced to deal with The Department of Indian and Northern Development, women who had to contact abusive ex-spouses or immigrant women forced to seek documentation in other countries.

Added to which, these 'personal' verification measures were augmented by the coming together of data gathering systems which function to compare information on income tax returns, student loans and welfare benefits through enhanced automated computer networks. The Harris Tories even introduced a provincial fraud telephone hotline, granting anonymity to anyone who reports on welfare fraud. As Little reveals, callers are exonerated from responsibility and accountability for their accusations, opening a window for any number of personal grievances to be energized into vindictive attributions of welfare fraud. Since the invigoration of these surveillance mechanism, Little reported that over 10000 recipients have been cut off assistance, $89 \%$ of whom were women. The number is much higher if welfare reductions are considered, to the extent in 2000-01 17734 people were either reduced or terminated from social assistance. ${ }^{2}$ And what is so disappointing is that through the intersection of these categorical/computer assisted and individual-moralized monitoring techniques, there are no hearings, explanations or second chances under the Tories' 'Zero Tolerance' policy.

There is no doubt that the potential for the policing of welfare has been drastically enhanced with the sharing of information across government sites, but what these examples of welfare policing serve to highlight is the intersection of 'new' and 'old' forms of surveillance. The most devastating consequence of amendments to Ontario welfare surveillance came in August of 2001, when college student Kimberly Rogers died eight months' pregnant while under 'house arrest' in her apartment. Purported by anti-poverty activists to have succumbed to extreme temperatures of the late summer, Rogers was legally confined to her apartment for six months when it was discovered through verification measures she had accessed the provincial student loan fund at the same time as she was accessing welfare. The dangers of 'leaky containers' and risk management techniques had never been so devastatingly revealed in Ontario under the auspices of the Harris government's

\footnotetext{
${ }^{2}$ Ontario Welfare Fraud Control Report, 2000-1.Government of Ontario
} 
'common sense revolution'. Amazingly as the inquest into the death of Kimberly Rogers commenced, calls for biometric finger scanning to prevent 'double-dipping' could be heard as the Tories' second term in office continued. Essentially, what the new measures function to do is create rather than detect conditions of fraud, revealing surveillance as a cause as well as an effect of intensified forms of social monitoring and information gathering. In the end, when the morally-laden language of fraud and verification is removed, what remains are prejudicial evaluations, populist underpinnings and poor women confronted with ever increasing intrusions into their personal lives in the pursuit to feed and clothe their families. ${ }^{3}$

\section{Conclusion}

Reflecting on the emergence of the cross-disciplinary initiative which is fast becoming recognized as surveillance studies, Lyon (2002:3) postulates that if the modern world demonstrated an inclination towards classification, this urge is endemic to the surveillance society. Involving a diverse range of activities and processes, it is not merely that the top-down apparatus of surveillance has been transformed into a flexible assemblage. Rather, he maintains that although social sorting and the 'phenetic fix' have taken on an increased salience over the past two decades, particularly after 11 September 2001, we still lack an exact understanding of the rise and workings of contemporary surveillance. The foregoing analysis has offered one explanation to this effect, explicating how the fusion of synoptical forces and panoptic desires contribute to the reinforcement of already existing social fractures.

And still, a degree of caution must be exercised concerning the extent to which the synoptic should be embraced as a totalizing, deterministic space. In light of the growing body of literature demonstrating how the contemporary news media represent a privileged discursive space where political agendas are not only constituted but contested and reconfigured, sensitivity to the complex relationship existing between the media and society, politics and social control is required. For it is not that the ideological influences of media narratives derive exclusively from the sources and contents of news reporting, as Mathiesen suggests, but that media narratives embedded in complex discursive formations operate in fluid and, often, contradictory ways. This is not to imply that Matheisen's identification of the mainstream media as a cultural gestalt tailored to the instrumental needs of western capitalism is unwarranted, and surely the effects of intensified monitoring practices are felt materially by those single mothers in Ontario who rely on welfare for their survival. That said, it is necessary to comprehend the news media as operating in the context of a more delicate- and less deterministic - web of relations. For it is entirely conceivable that popular representations of Kimberly Rogers as 'welfare scourge' could be transformed to symbolize the inhumanity and brutality of intensified forms of surveillance practices concerning

\footnotetext{
${ }^{3}$ Little, Margaret 2002 'Overseers of the Welfare State’, Presentation at Queens University (14 November)
} 
poor single mothers in Ontario.

In this regard, contemporary surveillance practices may best be understood to operate along a continuum where, in the spirit of the assemblage, at one extreme there resides a categorical seduction involving participatory forms of surveillance where more and more personal information is offered up by consumers who are seduced by consumer convenience and rewards. At the other extreme, and left under-explored in the assemblage model, is a categorical suspicion, which entails profiling of any number of socially perceived dangerous groups (Lyon 2003). This raises the more general point that although surveillance may be rhizomatic today, the shoots that the assemblage spawns are always amendable to incorporation by a range of political agendas and aspirations and often enjoy popular support. To return to an earlier example, following the terrorist attacks in New York and Washington a variety of surveillance mechanisms were put in place, including internet tracking devices, advances in airport security, CCTV monitoring, biometric measurements, smartcards, and email and telephone surveillance systems, all of which served to augment the control of those who are in positions to coordinate and administer social life. Far from a partial leveling of surveillance hierarchies constituted outside the state, the 'apparatus' has made a strong revival by exploiting the shoots of the 'assemblage', and this revival has been at least partially consolidated through the synoptically revealed interests of safety, security and anti-terrorism.

In consequence, taking seriously the analytic import of the synoptic, scholarly discourse may better appreciate the social and cultural foundations to the selectivity of the surveillant gaze as the culmination of synoptically mediated desires towards the panoptical aspirations of order and social control. This is not to dismiss the importance of other developments in the technological capabilities of surveillance, but there is a danger in losing site of the moralized and stigmatized components of techno-innovations in surveillance. The latter is of central importance, as it speaks directly to the appropriate formation of sites of resistance as social and discursive, not technological, in nature.

\section{References}

Deleuze, G. and F. Guattari (1987) A Thousand Plateaus. Minneapolis: University of Minnesota Press.

Ericson, R. and K. Haggerty (1997) Policing the Risk Society. Toronto: University of Toronto Press.

Foucault, M. (1977) Discipline and Punish. New York: Pantheon.

Gilliom, J. (1997) Everyday surveillance, everyday resistance. Studies in Law, Politics and Society, 16: 275-97. 
Gilliom, J. (2001) Overseers of the Poor: Surveillance, Resistance and the Limits of Privacy. Chicago: University of Chicago Press.

Haggerty, K. and R. Ericson (2000) The surveillant assemblage. British Journal of Sociology, 51(4): 605-622.

Hay, C. (1996) Mobilization through interpellation: James Bulger, juvenile crime and the construction of a moral panic. Social and Legal Studies, 4: 197-223.

Hier, S. P. (2003 forthcoming) The mortality of moral panic: risk, governance and contemporary moral politics. In C. Krinsky (ed.) The Sky is Falling.

Hunt, A. (1999) Governing Morals. Cambridge: Cambridge University Press.

Knight, G. (1998) Hegemony, the media and new right politics: Ontario in the late 1990s. Critical Sociology, 24(1-2): 105-129.

Little, M. (1994) 'Manhunts' and 'Bingo Blabs': the moral regulation of Ontario single mothers. Canadian Journal of Sociology, 19(2): 233-47.

Little, M. (1997) No Car, No Radio, No Liquor Permit: The Moral Regulation of Single Mothers in Ontario. Toronto: Oxford University Press.

Little, M. (1999) 'The pecker detectors are back': regulation of the family form in Ontario welfare policy. Journal of Canadian Studies, 34(2): 110-136.

Little, M. (2001) A litmus test for democracy: the impact of Ontario welfare changes on single mothers. Studies in Political Economy, 66: 9-36.

Lyon, D. (2001) Surveillance Society: Monitoring Everyday Life. Buckingham: Open University Press.

Lyon, D. (2002) Surveillance Studies: Understanding Visibility, Mobility, and the Phenetic Fix. Surveillance and Society, 1(1): 1-7. At: http://www.surveillance-and-society/articles1/editorial.pdf

Lyon, D. (2003) Surveillance After September 11. Cambridge: Polity.

Marvin, C. (1988) When Old Technologies Were New. New York: Oxford.

Mathiesen, T. (1997) The viewer society: Michel Foucault's 'Panopticon' revisited. Theoretical Criminology, 1(2): 215-234. 